\title{
NEW STABILITY INDICATING METHOD DEVELOPMENT AND VALIDATION OF CAPECITABINE AND DOCETAXEL IN BULK AND PHARMACEUTICAL DOSAGE FORM BY USING RP-HPLC
}

\author{
NEEHARIKA TIRUMALASETTYa, RAMCHANDRAN D.*
}

a*Department of Chemistry, Acharya Nagarjuna University, Nagarjuna Nagar, Guntur, Andhra Pradesh 522510, India

Email: ramchandran.anitha19@gmail.com

Received: 21 Jun 2021, Revised and Accepted: 28 Jul 2021

\section{ABSTRACT}

Objective: The current investigation was pointed at developing and progressively validating novel, simple, responsive and stable RP-HPLC method for the measurement of active pharmaceutical ingredients of Capecitabine and Docetaxel.

Methods: A simple, selective, validated and well-defined stability that shows gradient RP-HPLC methodology for the quantitative determination of Capecitabine and Docetaxel. The chromatographic strategy utilized Inertsil ODS column of dimensions $250 \times 4.6 \mathrm{~mm}, 5 \mathrm{micron}$, using isocratic elution with a mobile phase of acetonitrile and water (50:50). A flow rate of $1 \mathrm{ml} / \mathrm{min}$ and a detector wavelength of $220 \mathrm{~nm}$ utilizing the PDA detector were given in the instrumental settings. Using the impurity-spiked solution, the chromatographic approach was streamlined. Validation of the proposed method was carried out according to an international conference on harmonization (ICH) guidelines.

Results: LOD and LOQ for the two active ingredients and their impurities were established with respect to test concentration. The calibration charts plotted were linear with a regression coefficient of $\mathrm{R}^{2}>0.999$, means the linearity was within the limit. Recovery, specificity, linearity, accuracy, robustness, ruggedness were determined as a part of method validation and the results were found to be within the acceptable range.

Conclusion: The proposed method to be fast, simple, feasible and affordable in assay condition. During stability tests, it can be used for routine analysis of production samples and to verify the quality of drug samples during stability studies.

Keywords: Capecitabine, Docetaxel, RP-HPLC, Development, Validation

(C) 2021 The Authors. Published by Innovare Academic Sciences Pvt Ltd. This is an open access article under the CC BY license (https://creativecommons.org/licenses/by/4.0/) DOI: https://dx.doi.org/10.22159/ijap.2021v13i5.42488. Journal homepage: https://innovareacademics.in/journals/index.php/ijap

\section{INTRODUCTION}

Capecitabine, commonly known as Xeloda, is a chemotherapy $[1,2]$ medication that is used to treat breast cancer [3, 4], gastric cancer [5], and colorectal cancer [6]. In the treatment of breast cancer, it's usually coupled with docetaxel. It is taken by mouth. The most common side effects include abdominal discomfort [7], vomiting, diarrhoea, weakness, and rashes. Side effects include blood coagulation problems [8], allergic reactions [9], heart problems such cardiomyopathy [10], and low blood cell counts. It is not recommended for people with kidney disorders [11]. The infant may be damaged if this product is used during pregnancy. Capecitabine is converted to 5-fluorouracil (5-FU) inside the body, which is how it functions. It is a fluoropyrimidine, which contains 5 -fluorouracil and tegafur [12]. Colorectal cancer (as neoadjuvant therapy with radiation, adjuvant therapy, or for metastatic cases), Breast cancer (metastatic or as monotherapy/combotherapy; this is licenced as a second-line treatment in the UK), Gastric cancer (off-label in the US; this is a licenced indication in the UK), and Oesophageal cancer [13]. (offlabel in the US; this is a licenced indication in the UK).

Docetaxel (DTX or DXL) is a chemotherapeutic medication used to treat cancer. Taxotere and other trade names are used to market it. This includes breast cancer, head and neck cancer [14, 15], stomach cancer, prostate cancer [16], and non-small-cell lung cancer [17]. It can be used alone or with other chemotherapy medicines. A slow injection into a vein is used to administer it. Hair loss, cytopenia (low blood cell counts), numbness, shortness of breath, vomiting, and muscle pains are all frequent side effects of this medication. Allergies and the possibility of cancer are two more serious side effects. Side effects are more common in people with hepatic problems [18]. It is possible that using it while pregnant is detrimental to the foetus. The taxane class of medicines includes docetaxel. It works by interfering with the normal action of microtubules, which prevents cell division [19]. Breast, lung, prostate, stomach, head and neck, and ovarian cancers are all treated with docetaxel, a chemotherapy medication. According to clinical evidence [20], docetaxel has cytotoxic effects against breast, colorectal, lung, ovarian, prostate, liver, renal, gastric, and head and neck cancers, as well as melanoma. In hormone-refractory prostate cancer [21], docetaxel extends life expectancy and improves overall quality of life. The goal of this study is to use RP-HPLC to develop and validate methods for Capecitabine and Docetaxel.<smiles>CCCCCCOC(=O)Nc1nc2n(c(=O)n1)[C@@H]1O[C@H](C)[C@H](O)[C@H]1O2</smiles>

Fig. 1: Structure of (A) Capecitabine and (B) Docetaxel 


\section{MATERIALS AND METHODS}

\section{Chemicals}

Acetonitrile, HPLC-grade ortho phosphoric acid, water, were purchased from Merck India Ltd, Mumbai, India. APIs of Capecitabine, Docetaxel standards were procured from Dr. Reddy's laboratory, Hyderabad.

\section{The instrumentation}

Waters alliance liquid chromatography (model 2695) monitored with empower 2.0 data handling system and a detector of photo diode array (model 2998) was used for this study [22, 23].

\section{Method optimization}

To optimize the chromatographic conditions, different ratios of phosphate buffer and the acetonitrile in the mobile phase with isocratic and gradient mode was tested. However the mobile phase composition was modified at each trial to enhance the resolution and also to achieve acceptable retention times. Finally $0.1 \%$ OPA buffer and acetonitrile with isocractic elution was selected because it results in a greater response of active pharmacy ingredients. During the optimization of the method various stationary phases such as $\mathrm{C}_{8}, \mathrm{C}_{18}$ phenyl and amino, inertsil ODS columns were tested. From these trials the peak shapes were relatively good with a inertsil ODS column of $250 \times 4.6 \mathrm{~mm}, 5 \mu$ with a PDA detector. The mobile phase flow rate has been done at $220 \mathrm{~nm}$ in order to obtain enough sensitivity. By using above conditions we get retention times of Capecitabine and Docetaxel were about 3.483 and $4.076 \mathrm{~min}$ with a tailing factor of 1.05 and 1.08 . The number of theoretical plates for Capecitabine and Docetaxel were 5218,6784 which indicate the column's successful output the \% RSD for six replicate injections was around $0.15 \%, 0.24 \%$. The proposed approach suggests that it is extremely precise. According to ICH guidelines, the method established was validated.

\section{Validation procedure}

According to ICH Q2 (R1) guidelines [24, 25], analytical parameters such as system appropriateness, precision, specificity, accuracy, linearity, robustness, LOD, LOQ, forced deterioration, and stability were validated.

\section{Preparation of buffer}

$1 \mathrm{~L}$ of HPLC grade water was taken and filter through $0.45 \mu$ filter paper.

\section{Chromatographic conditions}

The HPLC analysis was performed on reverse phase HPLC system with isocratic elution mode using a mobile phase of acetonitrile and water and Inertsil ODS column $(250 \times 4.6 \mathrm{~mm}, 5 \mu)$ column with a flow rate of $1 \mathrm{ml} / \mathrm{min}$.

\section{Diluent}

Mobile phase was used as diluent.

\section{Preparation of the standard stock solution}

For standard stock solution preparation, add $70 \mathrm{ml}$ of diluents to $150 \mathrm{mg}$ of Capecitabine and $40 \mathrm{mg}$ of Docetaxel taken in a $100 \mathrm{ml}$ volumetric flask and sonicate for $10 \mathrm{~min}$ to fully dissolve the contents and then make up to the mark with diluent.

\section{Preparation of standard solution}

$1 \mathrm{ml}$ of solution is drawn from the above normal stock solution into a $10 \mathrm{ml}$ volumetric flask and diluted up to the level.

\section{Preparation of sample solution}

Take the Capecitabine sample weight equivalent to $150 \mathrm{mg}$ and the Docetaxel sample weight equivalent to $40 \mathrm{mg}$ into a $100 \mathrm{ml}$ volumetric flask and add $70 \mathrm{ml}$ of diluents and sonicate for $10 \mathrm{~min}$ to fully dissolve the contents and then make up the mark with diluent. This solution is filtered into a device using a $0.45 \mu$ nylon syringe in a vial.

\section{RESULTS AND DISCUSSION}

The main analytical challenge during development of a new method was to separate active Pharma ingredients. In order to provide a good performance the chromatographic conditions were optimized.

\section{System suitability}

In System suitability injecting standard solution and reported USP tailing and plate count values are tabulated in table 1 [26].

Table 1: Results of system suitability

\begin{tabular}{|c|c|c|c|}
\hline \multirow[t]{2}{*}{ System suitability parameter } & \multirow[t]{2}{*}{ Acceptance criteria } & \multicolumn{2}{|l|}{ Drug name } \\
\hline & & Capecitabine & Docetaxel \\
\hline USP Plate Count & NLT 2000 & 5218 & 6784 \\
\hline USP Tailing & NMT 2.0 & 1.05 & 1.08 \\
\hline USP Resolution & NLT 2.0 & - & 4.25 \\
\hline$\%$ RSD & NMT 2.0 & 0.15 & 0.24 \\
\hline
\end{tabular}

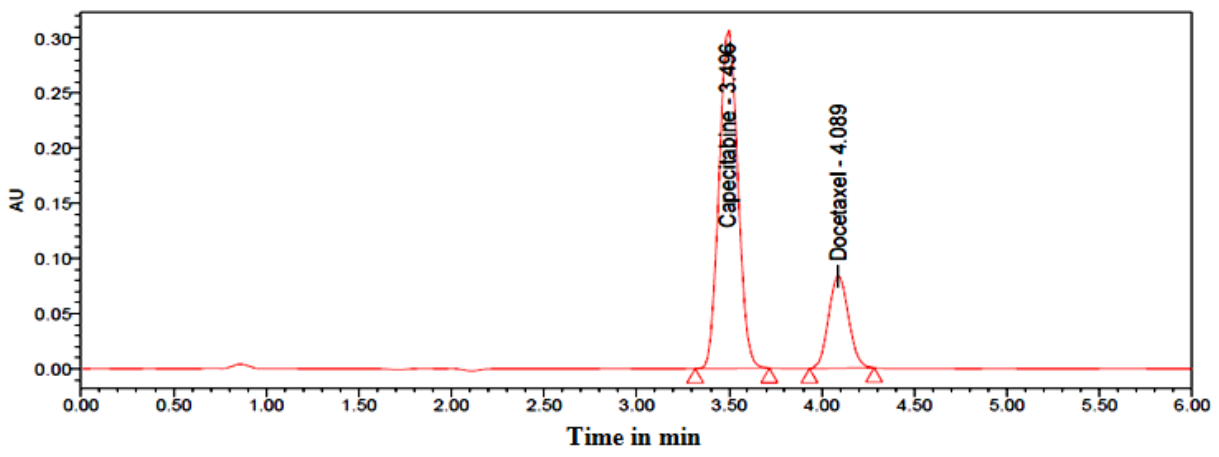

Fig. 2: Chromatogram of system suitability

\section{Specificity}

In this test method placebo, sample and standard solutions were analyzed individually to examine the interference. The below fig. shows that the active ingredients were well separated from blank and their excipients and there was no interference of placebo with the principal peak. Hence the method is specific.

\section{Linearity}

The area of the linearity peak versus different concentrations has been evaluated for Capecitabine, Docetaxel, as 10,25,50,100,125,150 percent respectively. Linearity was performed in the range of 15$225 \mu \mathrm{g} / \mathrm{ml}$ of Capecitabine and $4-60 \mu \mathrm{g} / \mathrm{ml}$ of Docetaxel. The correlation coefficients achieved greater than 0.999 for all. 


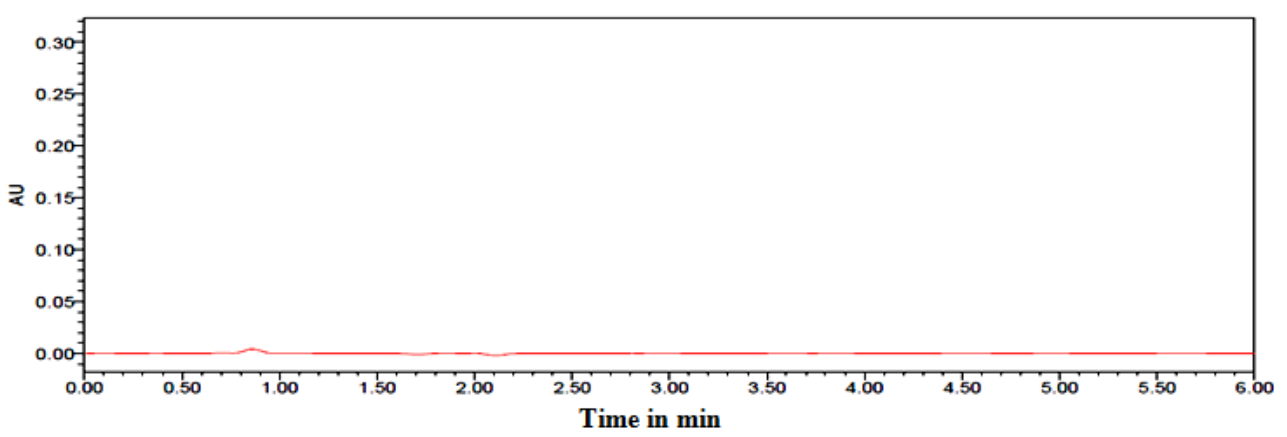

Fig. 3: Chromatogram of blank

Table 2: Linearity of capecitabine and docetaxel

\begin{tabular}{|c|c|c|c|c|}
\hline S. No. & Conc. $\mu \mathrm{g} / \mathrm{ml}$ & Capecitabine area count & Conc. $\mu \mathrm{g} / \mathrm{ml}$ & Docetaxel area count \\
\hline 1 & 15.00 & 258931 & 4.00 & 66921 \\
\hline 2 & 37.50 & 708643 & 10.00 & 164529 \\
\hline 3 & 75.00 & 1302567 & 20.00 & 326928 \\
\hline 4 & 150.00 & 2653415 & 40.00 & 642371 \\
\hline 5 & 187.50 & 3286934 & 50.00 & 813624 \\
\hline 6 & 225.00 & 3976582 & 60.00 & 975632 \\
\hline Correl coef & & 0.99990 & & 0.99996 \\
\hline Slope & & 17589.23 & & 16207.20 \\
\hline intercept & & 7214.58 & & 1125.73 \\
\hline
\end{tabular}

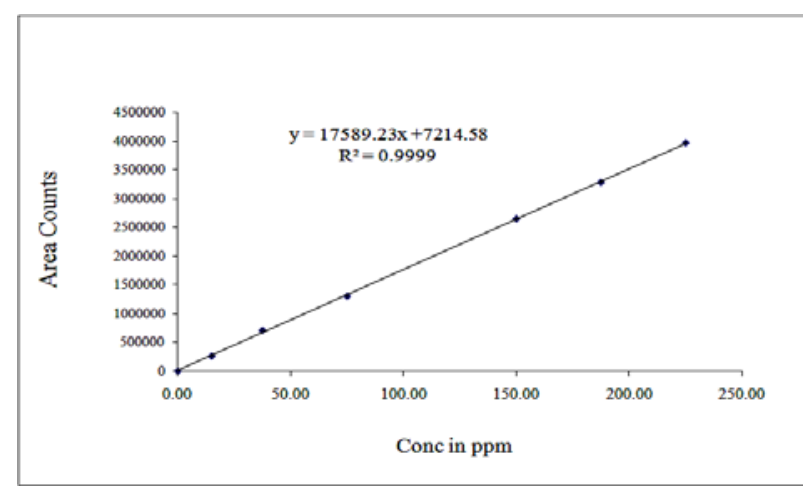

A

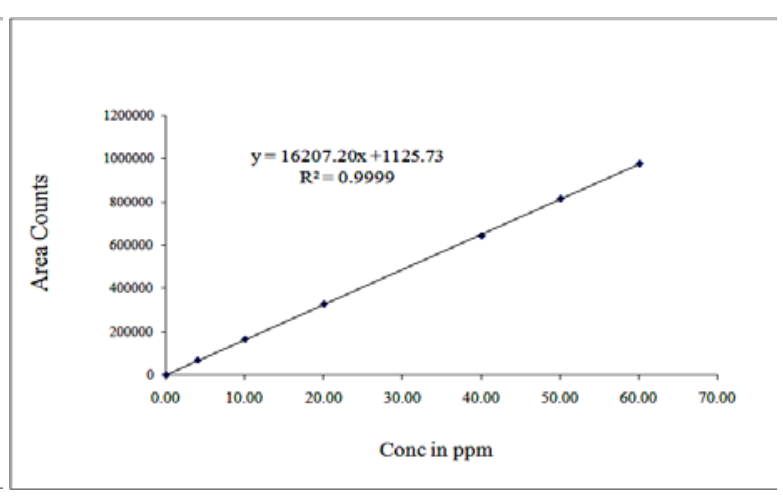

B

Fig. 4: Calibration plots of (A) Capecitabine (B) Docetaxel

\section{Accuracy}

In this method, Accuracy was conducted in triplicate by analyzing active pharma ingredient sample solution at three kinds of concentration levels of 50,100 and $150 \%$ of each at a specified limit. Percentage recoveries were measured and found to be within the limit. The accuracy and reliability of the developed method were established. The percentage recovery values were found to be in the range of $98.74 \%-99.98 \%$ for Capecitabine and $98.54-99.728 \%$ for Docetaxel. The results are given in table 3,4 and 5 .

\section{Precision}

In method precision study prepare six different samples in the concentration of Capecitabine (150 ppm) and Docetaxel (40 ppm) are injected into HPLC system. Capecitabine \%assay found to be in the range of $99.75 \%-100.75 \%$ and Docetaxel \%assay found to be in range of 98.23\%-100.01. These results are given below table 4 .

\section{Intraday precision}

Six replicates of a sample solution containing Capecitabine $(150 \mu \mathrm{g} / \mathrm{ml})$ and Docetaxel $(40 \mu \mathrm{g} / \mathrm{ml})$ were analysed on the same day. Peak areas were calculated, which were used to calculate mean, $\mathrm{SD}$ and \%RSD values.

\section{Interday precision}

Also called Intermediate precision. In this six replicates of a sample solution containing Capecitabine $(150 \mu \mathrm{g} / \mathrm{ml})$ and Docetaxel $(40 \mu \mathrm{g} / \mathrm{ml})$ were analysed on a different day. Peak areas were calculated which were used to calculate mean, SD and \%RSD values. The present method was found to be precise as the RSD values were less than $2 \%$ and also the percentage assay values were close to be $100 \%$. The results are given in table 5 .

\section{LOD and LOQ}

The LOD concentrations for Capecitabine are $0.188 \mu \mathrm{g} / \mathrm{ml}$ and $\mathrm{s} / \mathrm{n}$ values is 6 and Docetaxel $0.05 \mu \mathrm{g} / \mathrm{ml}$ and $\mathrm{s} / \mathrm{h}$ value 4 . The LOQ concentration for Capecitabine $0.62 \mu \mathrm{g} / \mathrm{ml}$ and their s/n values are 25 and Docetaxel their $0.165 \mu \mathrm{g} / \mathrm{ml}$ and $\mathrm{s} / \mathrm{n}$ value is 24 . The method is validated as per the US FDA guidelines [27].

\section{Robustness}

The conditions of the experiment were designed to test the robustness of established system intentionally altered, such as flow rate, mobile phase in organic percentage in all these varied conditions. Robustness results for Capecitabine and Docetaxel found to be within the limit and results are tabulated in table 7 . 
Table 3: Results of accuracy

\begin{tabular}{llll}
\hline S. No. & \% Level & Capecitabine \% recovery & Docetaxel \% recovery \\
\hline 1 & 50 & 99.98 & 99.72 \\
2 & 100 & 99.63 & 99.10 \\
3 & 150 & 98.74 & 98.54 \\
mean & & 99.45 & 99.12 \\
SD & & 0.64 & 0.59 \\
\hline
\end{tabular}

Mean+SD $(n=3)$

Table 4: Intraday precision results of capecitabine and docetaxel

\begin{tabular}{|c|c|c|c|c|c|c|}
\hline \multicolumn{4}{|c|}{ Capecitabine } & \multicolumn{3}{|l|}{ Docetaxel } \\
\hline S. No. & Conc. $(\mu \mathrm{g} / \mathrm{ml})$ & Area counts & \% Assay as is & Conc. $(\mu \mathrm{g} / \mathrm{ml})$ & Area counts & \% Assay as is \\
\hline 1 & & 2653102 & 99.99 & & 658874 & 99.63 \\
\hline 2 & 150 & 2674513 & 100.72 & 40 & 655321 & 98.31 \\
\hline 3 & & 2623050 & 99.63 & & 654382 & 100.01 \\
\hline 4 & & 2631204 & 99.75 & & 654763 & 99.85 \\
\hline 5 & & 2675843 & 100.48 & & 653285 & 98.23 \\
\hline 6 & & 2663215 & 100.15 & & 656498 & 98.65 \\
\hline$\%$ RSD & 0.84 & & & 0.298 & & \\
\hline mean & 100.12 & & & 99.11 & & \\
\hline SD & 0.421 & & & 0.807 & & \\
\hline
\end{tabular}

Mean+SD $(n=6)$

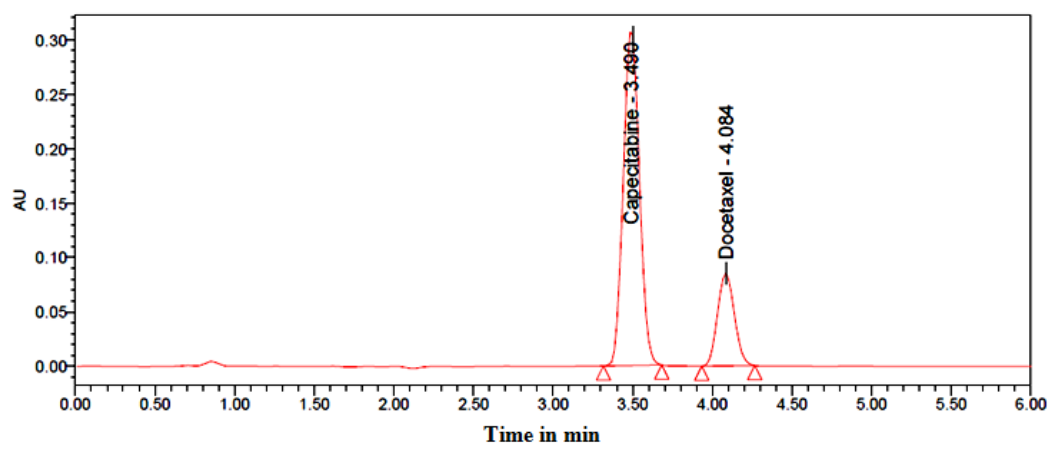

Fig. 5: Chromatogram of sample

Table 5: Inter-day outcomes of accuracy of capecitabine and docetaxel

\begin{tabular}{|c|c|c|c|c|c|c|}
\hline \multicolumn{4}{|c|}{ Capecitabine } & \multicolumn{3}{|l|}{ Docetaxel } \\
\hline S. No. & Conc. $(\mu \mathrm{g} / \mathrm{ml})$ & Area counts & \% Assay as is & Conc. $(\mu \mathrm{g} / \mathrm{ml})$ & Area count & \% Assay as is \\
\hline 1 & & 2648531 & 100.64 & & 648579 & 100.17 \\
\hline 2 & 150 & 2657482 & 100.12 & 40 & 643258 & 100.09 \\
\hline 3 & & 2635962 & 100.38 & & 643982 & 100.32 \\
\hline 4 & & 2685471 & 100.52 & & 643251 & 100.45 \\
\hline 5 & & 2665392 & 100.16 & & 643985 & 100.47 \\
\hline 6 & & 2653244 & 100.47 & & 647821 & 100.52 \\
\hline$\%$ RSD & 0.63 & & & 0.37 & & \\
\hline Mean & 100.38 & & & 100.34 & & \\
\hline SD & 0.206 & & & 0.175 & & \\
\hline
\end{tabular}

Mean+SD $(n=6)$

Table 6: LOD and LOQ for capecitabine and docetaxel

\begin{tabular}{|c|c|c|c|c|c|c|c|}
\hline \multicolumn{4}{|l|}{ Capecitabine } & \multicolumn{4}{|l|}{ Docetaxel } \\
\hline LOD & & LOQ & & LOD & & LOQ & \\
\hline Concentration & $\mathrm{s} / \mathrm{n}$ & Concentration & $\mathrm{s} / \mathrm{n}$ & concentration & $\mathrm{s} / \mathrm{n}$ & Concentration & $\mathrm{s} / \mathrm{n}$ \\
\hline $0.188 \mu \mathrm{g} / \mathrm{ml}$ & 6 & $0.62 \mu \mathrm{g} / \mathrm{ml}$ & 25 & $1.818 \mu \mathrm{g} / \mathrm{ml}$ & 4 & $0.165 \mu \mathrm{g} / \mathrm{ml}$ & 24 \\
\hline
\end{tabular}

Table 7: Robustness data of capecitabine and docetaxel

\begin{tabular}{lll}
\hline Parameter name & \% RSD & Docetaxel \\
\cline { 2 - 3 } & Capecitabine & 0.76 \\
Flow minus $(0.8 \mathrm{ml} / \mathrm{min}$ & 0.46 & 0.94 \\
Flow plus $(1.2 \mathrm{ml} / \mathrm{min})$ & 0.77 & 0.38 \\
Organic minus $(-10 \%)$ & 1.21 & 1.04 \\
Organic plus $(+10 \%)$ & 1.86 & \\
\hline
\end{tabular}




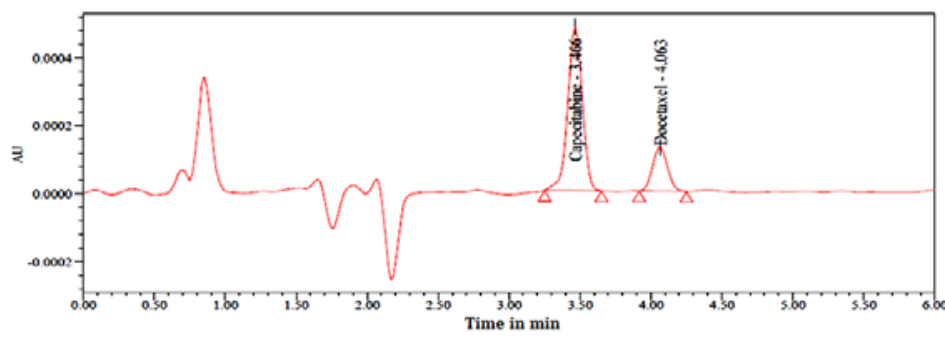

A

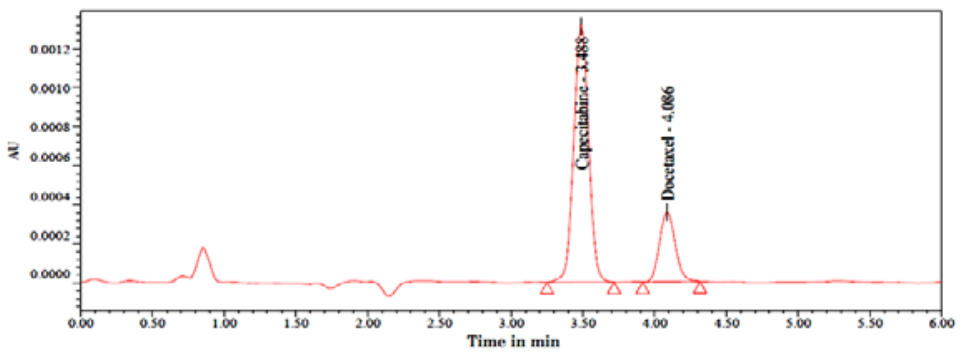

B

Fig. 6: Chromatogram of (A) LOD and (B) LOQ

\section{Stability}

The standard and sample solution was kept at room temperature and at $2-8{ }^{\circ} \mathrm{C}$ up to $24 \mathrm{~h}$. Then these solutions were pumped into the device and calculate the $\%$ of deviation from initial to $24 \mathrm{~h}$ [28].
There was no significant deviation observed and confirmed that the solutions were stable up to $24 \mathrm{~h}$ percentage of the assay was not quite $2 \%$. There is no effect in storage conditions for Capecitabine and Docetaxel drugs. The results are given below table 8 .

Table 8: Stability results of capecitabine and docetaxel

\begin{tabular}{llll}
\hline Stability & Capecitabine & Docetaxel \\
\cline { 2 - 4 } & Purity & \% of deviation & Purity \\
\hline Initial & 99.99 & 0.01 & 99.98 \\
$6 \mathrm{~h}$ & 99.55 & 0.48 & 99.64 \\
$12 \mathrm{~h}$ & 99.13 & 0.87 & 99.14 \\
$18 \mathrm{~h}$ & 98.76 & 1.24 & 98.83 \\
$24 \mathrm{~h}$ & 98.42 & 1.58 & 98.52 \\
\hline
\end{tabular}

\section{Degradation studies}

The Docetaxel and Capecitabine sample was subjected into various forced degradation conditions to effect partial degradation of the drug. Studies of forced degradation [29] have carried out to find out that the method is suitable for products of degradation $[30,31]$. In addition, the studies provide details about the conditions during which the drug is unstable, in order that the measures are often taken during formulation to avoid potential instabilities [32].

\section{Acid degradation}

Acid degradation was done at $1 \mathrm{~N} \mathrm{HCl}$ and degradation was formed $12.41 \%$ for Capecitabine and $13.22 \%$ for Docetaxel.

\section{Alkali degradation}

Alkali degradation was done at $1 \mathrm{~N} \mathrm{NaOH}$ and degradation was formed $12.36 \%$ for Capecitabine and $13.48 \%$ for Docetaxel.

\section{Peroxide degradation}

Peroxide degradation was done at 20\% hydrogen peroxide and degradation was formed $13.47 \%$ Capecitabine and $15.42 \%$ for Docetaxel.

\section{Reduction degradation}

In reduction degradation, $11.59 \%$ Capecitabine and $12.54 \%$ Docetaxel degradation was observed.

\section{Thermal degradation}

In thermal degradation the sample was degraded to $10.63 \%$ of Capecitabine and $11.52 \%$ of Docetaxel.

\section{Degradation of hydrolysis}

In hydrolysis degradation the sample was degraded to $9.67 \%$ of Capecitabine and $10.47 \%$ of Docetaxel.

All degradation results are tabulated in table 9.

Table 9: Forced degradation results of capecitabine and docetaxel

\begin{tabular}{llll}
\hline Degradation condition & Capecitabine & \multicolumn{2}{c}{ Docetaxel } \\
\cline { 2 - 4 } & \% Assay & \% Deg & \% Assay \\
\hline Acid degradation & 87.59 & 12.41 & 86.78 \\
Alkali degradation & 87.64 & 12.36 & 86.52 \\
Peroxide degradation & 86.53 & 13.47 & 13.22 \\
Reduction degradation & 88.41 & 11.59 & 84.58 \\
Thermal degradation & 89.37 & 13.48 & 87.46 \\
Hydrolysis degradation & 90.33 & 9.63 & 88.48 \\
\hline
\end{tabular}




\section{CONCLUSION}

We present in this article simple, selective, validated and welldefined stability that shows gradient RP-HPLC methodology for the quantitative determination of Capecitabine and Docetaxel. All the products of degradation formed during the stress conditions and the related active pharma ingredients are well separated and peaks were well resolved from each other and separate with an appropriate retention time indicating that the proposed method to be fast, simple, feasible and affordable in assay condition. Therefore the developed method during stability tests, it can be used for routine analysis of production samples and to verify the quality of drug samples during stability studies.

\section{ACKNOWLEDGEMENT}

The authors thankful to Shree Icon Pharmaceutical Laboratories for providing laboratory facilities to complete this research work.

\section{FUNDING}

Nil

\section{AUTHORS CONTRIBUTIONS}

All authors have contributed equally.

\section{CONFLICTS OF INTERESTS}

Declared none

\section{REFERENCES}

1. Roness H, Kalich Philosoph L, Meirow D. Prevention of chemotherapy induced ovarian damage possible roles for hormonal and non hormonal attenuating agents. Hum Reprod Update 2014;20:759-74.

2. Savage L.Chemotherapy induced pain puzzles scientists. J National Cancer Institute 2007;99:1070-1.

3. Eliassen AH, Hankinson SE, Rosner B, Holmes MD, Willett WC. Physical activity and risk of breast cancer among postmenopausal women. Arch Intern Med 2010;170:1758-64.

4. Kaiser J. Cancer cholesterol forges link between obesity and breast cancer. Science 2013;342:1028.

5. Paterson HM, McCole D, Auld CD. Impact of open-access endoscopy on detection of early oesophageal and gastric cancer 1994-2003. Population based study. Endoscopy 2006;38:503-7.

6. Yau, Tung On. Precision treatment in colorectal cancer. Now and the future. JGH Open 2019;3:361-9.

7. Tytgat GN. Hyoscine butylbromide a review of its use in the treatment of abdominal cramping and pain. Drugs 2007;67:1343-57.

8. Hunt, Beverley J. Bleeding and coagulopathies in critical care. $\mathrm{N}$ Engl J Med 2014;370:847-59.

9. May JR, Dolen WK. Management of allergic rhinitis. A review for the community pharmacist. Clin Ther 2017;39:2410-9.

10. Simpson S, Rutland P, Rutland CS.Genomic insights into cardiomyopathies. A comparative cross species review. Vet Sci 2017;4:19.

11. Moore EM, Bellomo R, Nichol AD. The meaning of acute kidney injury and its relevance to intensive care and anaesthesia. Anaesth Intensive Care 2012;40:929-48.

12. Caudle KE, Thorn CF, Klein TE, Swen JJ, McLeod HL, Diasio RB, et al. Clinical pharmacogenetics implementation consortium guidelines for dihydropyrimidine dehydrogenase genotype and fluoropyrimidine dosing. Clin Pharmacol Ther 2013;94:640-5.

13. Zhang Y. Epidemiology of esophageal cancer. World J Gastroenterol 2013;19:5598-606.
14. Chow, Laura QM. Head and neck cancer. $N$ Engl J Med 2020;382:60-72.

15. Specenier P, Vermorken JB. Advances in the systemic treatment of head and neck cancers. Curr Opinion Oncol 2010;22:200-5.

16. Norris JM, Simpson BS, Freeman A, Kirkham A, Whitaker HC, Emberton M. Conspicuity of prostate cancer on multiparametric magnetic resonance imaging. A cross disciplinary translational hypothesis. FASEB J 2020;34:14150-9.

17. Nasser, Nicola J, Gorenberg, Miguel, Agbarya, Abed. First line immunotherapy for non small cell lung cancer. Pharmaceuticals 2020;13:373.

18. Wang HJ, Gao B, Zakhari S, Nagy LE. Inflammation in alcoholic liver disease. Annu Rev Nutr 2012;32:343-68.

19. Chaaban S, Brouhard GJ.A microtubule bestiary structural diversity in tubulin polymers. Mol Biol Cell 2017;28:2924-31.

20. Lyseng Williamson KA, Fenton C. Docetaxel a review of its use in metastatic breast cancer. Drugs 2005;65:2513-31.

21. Shelley M, Harrison C, Coles B, Staffurth J, Wilt TJ, Mason MD. Chemotherapy for hormone refractory prostate cancer. Cochrane Database Syst Rev 2006;CD005247.

22. Subrahmanyam Talari, Anuradha V, Komala Sai Prathyusha A. New validated RP-HPLC method for cisplatin and topotecan in API and vaccine form and its stress studies. Int J Res Pharm Sci 2021;12:808-14.

23. Syed Rafi, Kantipudi Rambabu. Stability indicating validated HPLC method for the determination of aceclofenac and misoprostol in bulk and pharmaceutical formulation. Int J Res Pharm Sci 2020;11:7848-53.

24. Bhavani P, Prasada Rao K, Mohan S. Novel validated reversed phase high performance liquid chromatography method for determination of glucosamine, diacerein, and methyl sulfonyl methane in micro sample rat plasma and its application to pharmacokinetic and dissolution studies. Asian J Pharm Clin Res 2020;13:50-63.

25. Shivani CP, Maheshwari DG. Development and validation of UV spectrometric and HPLC method for estimation of escitalopram oxalate and flupentixol dihydrochloride in combined dosage form. Asian J Pharm Technol Innovations 2016;4:59-70.

26. Asha Eluru, Surendra Babu K. A study of method development, validation and forced degradation for simultaneous quantification of povidone iodine and ornidazole in bulk and pharmaceutical dosage form by using RP-HPLC. IJPSR 2021;12:1217-22.

27. Swati K, Abhishek P, Sushank S, Bothiraja C, Atmaram P. Highperformance liquid chromatography for the simultaneous estimation of cefoperazone and sulbactam in rat plasma and its importance in therapeutic drug monitoring. Int J Pharm Pharm Sci 2020;12:92-7.

28. Vijayakumari M, Balasekhar Reddy Ch. Stability indicating validated hplc method for the determination of zanubrutinib in bulk and pharmaceutical dosage form. Asian J Pharm Clin Res 2020;13:159-62.

29. Abdul Raziq, Syed Umer Jan. Relative comparison of stability and degradation of methylcobalamine tablets of different brands at different storage settings. Int J Appl Pharm 2021;13:171-5.

30. Rajakumari R, Sreenivasa Rao S. Stress degradation studies and development of a validated RP-HPLC method for determination of tiagabine in presence of its degradation products. Int $\mathrm{J}$ Pharm Pharm Sci 2016:8:230-6.

31. Charu Pandya P, Sadhana Rajput J. Development and validation of stability indicating method RP-HPLC method of acotiamide. Int J Pharm Pharm Sci 2018;10:1-8.

32. Birva Athavia A, Zarna Dedania R. Stability indicating HPLC method for determination of vilazodone hydrochloride. Int J Curr Pharm Res 2017;9:123-9. 